\title{
Does pneumoperitoneum increase or decrease the serum levels of interleukin-6?
}

\author{
György Weber
}

Published online: 15 July 2010

(C) Springer Science+Business Media, LLC 2010

I read with great interest the recently published article by Schmidt et al. [1] regarding the effect of carbon dioxide pneumoperitoneum. In the summary of their excellent

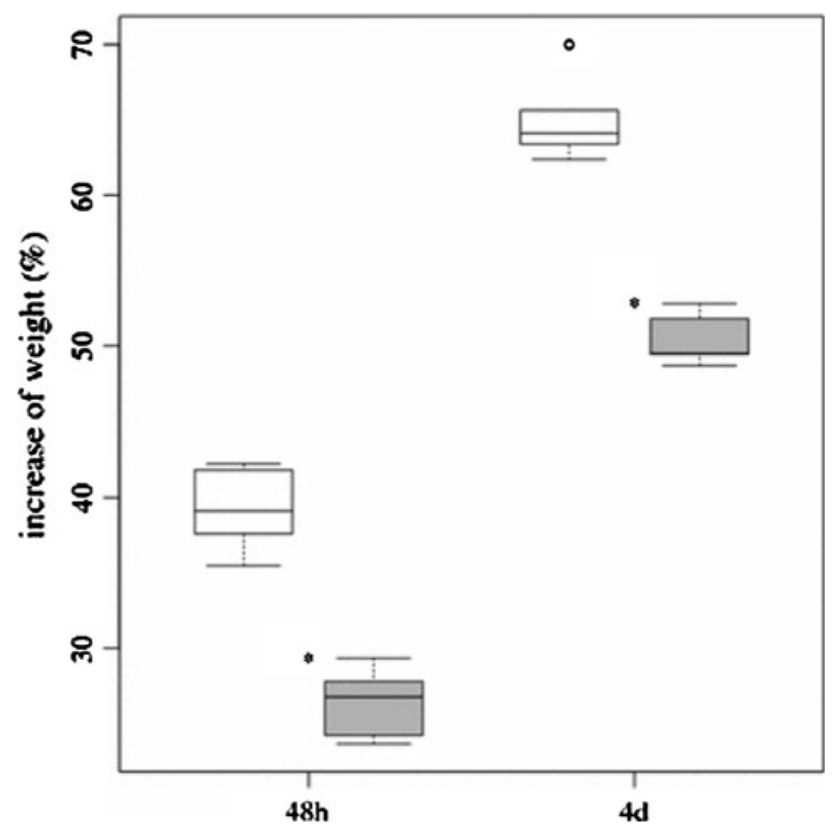

Fig. 3 Postoperative proinflammatory interleukin-6 (IL-6) at different postoperative time points. $* p<0.05$

G. Weber $(\bowtie)$

Department of Surgery, Medical Faculty University of Pécs,

Kodály Z. u. 20, 7624 Pecs, Hungary

e-mail: gyorgyweber@yahoo.com

G. Weber

Department of Surgical Research and Techniques, Medical

Faculty University of Pécs, Kodály Z. u. 20, 7624 Pecs, Hungary article, they conclude that the interleukin-6 (IL-6) level is significantly higher in the pneumoperitoneum group at $24 \mathrm{~h}$ and on day 4.

A completely contrasting result can be seen in Fig. 3 (postoperative proinflammatory IL-6 at different postoperative time points; $* p<0.05$ ), which shows significantly lower levels of something after $48 \mathrm{~h}$ and 4 days than in control animals. This contradiction is quickly solved as we read this article further. Figure 4A (effect of carbon dioxide pneumoperitoneum on liver regeneration as assessed by measurement of regenerating liver mass on days 2 and 4) correctly shows the postoperative proinflammatory IL-6 levels at different postoperative time points. The mixing of these figures is unfortunate.

Disclosures György Weber has no conflicts of interest or financial ties to disclose.

\section{Reference}

1. Schmidt SC, Schumacher G, Klage N, Chopra S, Neuhaus P, Neumann U (2010) The impact of carbon dioxide pneumoperitoneum on liver regeneration after liver resection in a rat model. Surg Endosc 24:1-8 